\title{
Psychotherapy, child abuse and the law
}

\author{
Roger KENNEDy, Consultant to the Family Unit, The Cassel Hospital, Richmond, \\ TW10 7JF
}

Those working with families in the field of child abuse often find themselves becoming intimately involved with Family Law. Although the involvement may produce confusion and frustration in professionals untrained in the law, it may also help facilitate appropriate and effective treatment of severely disordered families. I believe not only that legal framework can help those working in the mental health field, but also that a psychotherapeutic understanding of individuals, families and groups can aid lawyers steer families more effectively and humanely through the legal process. By the term psychotherapy I mean a body of theoretical and clinical knowledge concerned with looking at people's conflicts, feelings, anxieties and reasons for actions, which includes an understanding of the unconscious processes of the mind. A psychotherapeutic approach cannot provide a substantial basis for legal theory, for the latter is heavily weighted towards the notion of the 'reasonable' man, whose unconscious ideas and emotions are significant only if they lead to an intention to act illegally and the carrying out of the illegal act. However, the day-to-day practice of law may perhaps be enriched by a more rigorous attempt to understand human emotions, particularly in the often emotionally painful areas of Family Law. Moreover, I suspect that there are a number of shortcomings in the current complex, sometimes muddled, way that families have to deal with the law, which the proposed new legislation (DHSS, 1987) may not address. A psychotherapeutic understanding of some of the reasons for this muddle as well as of the general issues in this field may have benefits for lawyers, mental health workers and clients.

The Families Unit at the Cassel Hospital, Richmond, is the only substantial medical establishment with in-patient beds for whole families, and it can provide detailed and relatively safe observation and treatment of severely disordered families. Among the different kinds of family treated, we have had considerable experience with those who have neglected their children over years and have subjected them to one or more episodes of violent attacks. Such physical abuse, where there is a breach of what one could call the 'physical safety barrier', has occasionally been accompanied by sexual abuse and the breach of the better known 'incest barrier'.

A comprehensive description of the Families Unit treatment programme and of our work on child abuse has already been published (Kennedy et al, 1987; Kennedy, 1988). It is a psychotherapeutic setting where the needs and rights of the child are kept to the forefront of all treatment, and this includes detailed understanding of the inner world of thoughts, feelings and play of the child. Simultaneously, we aim to support the parents' own authority and capacity to look after their children by expecting them to take on a considerable responsibility for themselves and their children in a drug- free environment. The treatment programme consists of detailed nursing work focussed on everyday family activities and parenting skills, combined with intensive psychotherapy for the parents and, if necessary, for the children. We offer an initial month's assessment, followed by the possibility of about a year's treatment. We place great emphasis on monitoring at-risk families and making sure the children are safe. This means that when we admit families in which there has been abuse, we begin by having a strict plan around them which limits their freedom, until we can trust them. We then gradually allow them more freedom and responsibility as the admission proceeds. Approximately half of the ten families at any one time in the Unit have children in the care of their local authority or as Wards of the High Court. Much of the treatment of these families involves regular liaison with the relevant social work agency, frequent attendance at case conferences and occasional appearances by myself in the High Court. We are often used as a resource to establish whether or not a family is capable of being permanently rehabilitated. I shall use our experience to discuss some of the complicated issues arising from the interaction between families, the law and mental health workers.

\section{General issues}

In most of the families I am considering, the law has been invoked when a child has been severely physically harmed by one or more of its natural or stepparents. However, by this time the family may have reached a point of such severe breakdown that they cannot stay together as a unit, however much rehabilitation is subsequently attempted. The law at this point could be seen as offering an emergency escape route for the abused child. In other circumstances, the law may be invoked by mental health professionals at a time of family crisis in order to 
prevent abuse, such as by calling a case conference and asking the courts for a supervision order etc. The law in this case seems to provide a boundary for the professionals and the family through which the parents cannot step, if they wish to keep their children. Whether or not this manoeuvre actually helps the parents to be more effective in the long term is debatable, as there seems to be little research into the outcome of such interventions on future family functioning. It is certainly my impression that without simultaneous psychological treatment of the family, the invocation of the law does little except foster an unnecessary sense of persecution in the parents which may in the end put their children more at risk. By placing more emphasis on the parents' rights, the proposed reform of family law attempts to remedy this situation, to some extent. But I think that it still leaves the parents feeling merely threatened, unless there is some adequate psychological help for them. As these are often difficult parents, with whom such work can be anxiety provoking and frustrating, they and their children may need skilled psychotherapeutic understanding and handling, not merely supportive counselling which does not address the very complex issues involved in these matters and the powerful feelings evoked in the families and in those around them.

It is also my impression that once a family comes into contact with the law, then it is exceedingly difficult for the family to be free of it subsequently. I myself am not one of those who believe that treatment of abusing families always requires the intervention of the law. The law as currently organised seems to be particularly pedestrian, at times excessively bureaucratic and most tenacious. Although a child can be rescued quickly from danger, and although a child may be made a ward of court at short notice, as most people in the field are aware, the subsequent procedures for deciding what is in the best interests of the child can be lengthy and cumbersome - often at a time of the child's life when his/her need is for emotional and physical certainty. Thus, what may be necessary for legal and immediate clinical reasons may not in fact be in the long-term best interests of the child. We do not know if the delays that are necessary while all the factors are weighed in court damage the child, and how much children can subsequently recover from any damage at this time.

In essence, the authority of the law takes over from the parents to a greater or lesser extent when their own authority as parents, and their capacity to take responsibility for their children and keep them safe from harm, breaks down. What is at issue, both in the clinical setting and in the courts, is parenting capacity, which is difficult to define. I would suggest that parental capacity refers to the parents' capacity to allow and tolerate a child being dependent on them; and to appreciate the child's world, with its need for good enough physical and emotional security, reasonable flexibility, appropriate disciplining, warmth and understanding, on a daily basis. With many abusing parents, several of these basic elements of child care have broken down; they may often feel that they cannot take on their role as parents for the whole day for a variety of reasons, such as a lack of their own parenting, immaturity, envy towards their own children, severe marital discord and social pressures. The physical attack on their children is multidetermined. It is our experience (Kennedy, 1988) that the parents are often enormously threatened by the possibility of experiencing in themselves feelings of vulnerability and dependency. Attempts to do so, such as acknowledging their dependency on a partner or a professional worker, are not infrequently accompanied by acute suicidal feelings. Their children are as a consequence subjected to repeated breakdowns in parental affection, which if untreated in the community may result in physical abuse, as the end product of the parents' emotional precariousness. It is also our experience that those families who cooperate with treatment without subjecting their children to further abuse are those who can trust, to some extent, their professional workers, and can allow specific emotional contact with them. If a family is unable to allow trust to develop in spite of appropriate help, then it is likely that treatment will fail.

I have raised the issue of parental capacity, but there is also the related issue of parental authority, which I think essentially refers to the degree to which parents can fulfil their adult social responsibilities with regard to their children. The scope of parental authority is wide in legal terminology, and includes the following rights and duties: right to care, custody and possession; right to access; right to determine education and religion; right to discipline; right to consent to the child's marriage; right to consent to medical treatment; right to veto the issue of a passport and give consent to emigration; right to administer the child's property; right to appoint a guardian; right to agree to adoption and to consent to an application for custodianship; right to consent to change the child's surname; right to represent the child in legal proceedings; duty to secure the child's education; and duty to maintain, protect and represent the child in legal proceedings (Bromley \& Lowe, 1987). What the legal definitions leave out is how a parent may or may not feel they have any authority of their own, which may in turn lead them to neglect their duties. An inner conviction of the ability to sustain being a parent usually implies a reasonably secure upbringing and a reasonably adequate physical environment for the family, neither of which may be the case for large numbers of people. Many such people seem to get by without major family disruption, but there would seem to be an increasing number of people for whom the responsibility of 
parenthood provokes breakdown of their functioning as responsible members of the community. How such families relate to the authority of the law may be of great prognostic significance with regard to their capacity to change.

It is probably inevitable, given the law as it is currently organised, and the kind of families who need legal intervention, that the law and its representatives, particularly the social work agency, are seen as persecuting external authorities. The parents frequently complain to a greater or lesser extent of a feeling of being persecuted by social workers, doctors or lawyers. They very rarely complain about being understood or looked after. Some of their complaints seem to me justified when there is real persecution and intimidation by any agency, as I have occasionally come across in the families I have been referred. And I am sure much could be done to make the practice of family law more comprehensible to the clients and provide more backing for those parents who sincerely regret what they have done and wish to change.

More often than not, however, the sense of persecution the parents complain of is a mirror reflection, as it were, of their own inner feeling of being persecuted. The feeling may be conscious but the reasons for the feeling may be unconscious, that is, unknown to them. Such reasons may include the fact that the parents have frequently experienced real persecution in one form or another from their own parents, including at times physical and sexual abuse; although they may not have been abused as such as children, they may have suffered from severe emotional deprivation; and they may had an experience of an arbitrary, punitive father. Such environmental failures may be too painful for the parents to bear thinking about. Yet their own children may unconsciously remind them of their own deprivation. The birth and presence of a child are highly complex and powerful events for the adult. A child may awaken past conflicts and reopen old narcissistic wounds; the adult may be quite capable of inter-adult relations, but quite incapable of responding to the child. The child, or a particular child in a family, may come to represent the parents' unwanted bad parts. In extreme situations, the child's presence may precipitate such a disruption in mental functioning that the child will be subject to primitive and unmodified attacks at the hands of the adult. In a sense, one could understand this attack on their children as simultaneously an unconscious attack by the parents on their own persecuting 'inner' parents; the ones who, in reality or fantasy, neglected them.

We often see this 'internal attack' in those patients in the hospital who apparently want constant parenting, or appear very needy; and, yet, in spite of considerable efforts by staff and other patients, avoid using help. Instead, they constantly bite the hand that feeds them; while at the same time they appear quite unaware of the aggressive aspects of their demands. Such an attitude is not infrequently encountered by the families I am considering. The end result is that external authorities have to become parents for the children. And in a sense, at least in some of the families, this is a great relief to them, and of course to the children. But the motives behind the need to take over parental responsibility and the parents' need to give up their child are not necessarily faced. Once the authorities act as parents to the child, they will to some extent arouse feelings and yearnings in the actual parents to be looked after by the authorities in a way that they did not experience as children or adolescents. Yet the parents usually fight these yearnings and deny any sense of dependency on the authorities, complaining instead of being persecuted. They may take great pains to look for any tiny loophole in the caring and monitoring structure that is around them, rather than feel relief. It is in fact usually persecuting and sometimes humiliating for them to acknowledge openly their dependency needs. But if rehabilitation is to succeed, and if the parents are to take back responsibility for the children, the facing of these dependency issues is, in my opinion, fundamental.

Equally important for successful rehabilitation is the capacity of the workers around a family, including legal representatives, to understand, monitor and effectively deal wth the considerable anxiety that these families usually evoke. It is inevitable that workers will feel anxious about these cases; it can be even more worrying when workers do not feel anxious about them, for it may indicate some denial of the family's difficulties or danger. The workers' anxiety is made up of various elements: they have to be at the receiving end of the family's own general anxieties, they may have to take on worry and concern for the children in the absence of parental concern, they may have to face unconsciously representing figures from the family's past such as an unsatisfactory parent, and they may find that they have their own problems and anxieties touched or stirred up by the families they meet. Professionals may deal with these pressures in a variety of inappropriate ways, if they are unaware of what is happening. They may become excessively rigid, authoritarian, punitive or collusive. They may also act as if they were similar to the figures from the past transferred onto them. It is our experience that professionals need to maintain a subtle balance between protecting themselves from anxiety and being open enough to be available to deal with the family's anxieties. It is also our experience that such professional robustness requires considerable support and supervision from senior staff (Kennedy et al, 1987). 


\section{Clinical example}

I shall not attempt in this paper to illustrate all my general points, but instead I shall give one clinical example which concerned Wardship proceedings, in order to show some of the interaction between psychotherapy and the law in day to day work. Wardship jurisdiction means that legal control over the child's person and property is invested in the court, the court takes over responsibility of the child. No important step in the child's life can be taken without the court's consent. In general the principle upon which the court acts is that the welfare of the child is the first and paramount consideration (Lowe $\&$ White, 1986). One of the main advantage of using Wardship proceedings is that difficult and contentious cases can be heard by an experienced judge, who also has wide powers with respect to the ward.

\section{The 'C' family}

We are still in the middle of treating this difficult family, mother, father and their baby daughter 'Rachel', though we are optimistic about the outcome. There has been a complex interplay between clinical treatment and the law, involving much frustration, misunderstandings and anxiety for all parties. When they first saw me, following referral by their social worker, they denied any difficulties, and they also denied physically abusing previous children who were removed for adoption. I felt there was little we could do, but on firmly taking up their denial they then owned up to the previous abuse. However, they tended to blame the authorities in a blanket way for their difficulties. Mrs C's schizophrenic mother abandoned her at birth to the care of a punitive relative. She herself has felt that she was never mothered by someone who wanted her. $\mathrm{Mr} \mathrm{C}$ came across as a lonely, isolated man, prone to sudden outbursts of rage. In spite of their difficulties, both parents strongly wanted to look after their baby, who was made a Ward of Court because of the abuse of the previous children and the fragility of the family situation.

In the assessment month, the couple showed some ability and willingness to engage with us in treatment and to improve in their handling of Rachel. But we considered that we needed a particularly tight legal and clinical framework in order for treatment to succeed, because of the vulnerability of the mother and the father's tendency towards delinquency. This required new fostering arrangements for the weekend, and a graded plan of rehabilitation. However, the couple did not agree to our conditions, and through their solicitor insisted on disputing our view in court. On the day of hearing, I found myself doing what has now become common practice, that is, helping with my clinical input, two, or more parties (in this instance social services and the family), to sort out in the corridor what to present to the Judge. I actually believe that the family had had bad advice from their solicitor who had little idea of what treatment consisted and who seemed to want to take a belligerent attitude. Both barristers kept going from me to their clients in order to establish what was clinically feasible and what they could incorporate in a legal Order; and in the end the family agreed to the conditions of treatment. On the one hand, it seemed a waste of everyone's time to be dragged at short notice to court, but on the other I suspect that the parents had to see whether or not I, and the Family Unit, could withstand their onslaughts.

Although treatment went smoothly for some while, the next hiccup occurred when the family returned to court for a progress report. I was not invited to come, and I was asked only for a brief report. The father used the opportunity to make the Judge impatient with the Cassel about his therapy times. The father gave the erroneous impression that we were not giving him times that enabled him to continue his work, and the Judge appeared to agree with him. This apparently trivial episode put the treatment in jeopardy. The father used the fact that he appeared to have obtained backing for his actions to continue to be delinquent, frequently not coming to individual or marital sessions or appearing late, returning to the hospital late, and being generally dismissive and at times abusive to staff. The mother became increasingly out of touch with reality. Her therapist in particular felt that she was becoming psychotic. Earlier in the treatment she had experienced visual hallucinations of the children that were removed from her. Although we took the hallucinations seriously, at the same time we felt that they took place in the context of her beginning to mourn the loss of the children, and that the hallucinations thus had psychological meaning. In fact, they soon disappeared over a period of days, without medication. Nonetheless, their appearance was indicative of a psychotic predisposition, and at the point when the legal framework was breaking down, she appeared increasingly bizarre. For example, she felt she had a special relationship to me, and would often give me strange meaningful looks, as if indicating that she was a particularly important patient. While the husband was not psychotic, he did not help his wife keep her hold on reality as he was so often absent or inconsistent. Overall, the rehabilitation of the family was blocked. We had tried to push ahead with our graded plan to allow the couple increasing time alone with Rachel, but the couple were much too anxious to accept our proposals.

We were beginning to feel quite pessimistic about the outcome by the time of the next appearance in court. I had in fact written to the Judge to explain the reality of Mr C's therapy times, and on this occasion 
we presented a detailed report, and both myself and my senior registrar attended court. Our attendance was obviously necessary in order to reestablish the conditions of treatment. In fact, although the Judge showed great insight and understood the complexities of the case, Mr and Mrs C's lawyers tried both before and during the hearing to make it into an adversarial contest, which came near to jeopardising the whole framework. However it was clear to the Judge that we and the social service department were desperately trying to help the family and were not engaged in some competitive exercise. At the same time, it was made clear to all the parties that by the time of the next appearance, there had to be a definite opinion about whether or not rehabilitation was possible. In general I believe that, in order for rehabilitation to succeed, we need a partnership between ourselves and lawyers. Without this partnership, the mental health workers are left with having to pick up the pieces or having to carry excessive anxiety, as was the case with this family. In fact, soon after the court appearance, in which the framework for treatment was re-established, the treatment took off again, and the rehabilitation programme advanced. The mother became more in touch with reality and her husband became much more involved in treatment. Without his cooperation, a successful outcome would have been impossible, for he had an important role in providing a more realistic attitude to his daughter than his more psychologically vulnerable wife.

\section{Comment}

In my clinical example, I have chosen to outline some rather difficult treatment issues which have involved the law. I did so because I felt it was important to present the typically muddled situations with which we have to deal. In the example, the moment there appeared to be a weak point in the treatment framework, the rehabilitation of the family began to break down. The input of a psychotherapist was useful in allowing the parties to come to an acceptable legal decision. I was not looked on as some sort of strange monster speaking an alien tongue; on the contrary I was welcomed and was worked hard by the parties. The example also shows how delicate a balance has to be maintained in these cases between all the parties involved. The pathology of the families is such that they will look for loopholes in the holding structures, and, often against their own interests, attack the caretakers.

Parents have every right to go to law when they can and I am not disputing this at all. On the contrary, I sometimes feel that one of our main jobs is in fact to help often relatively uneducated and/or deprived families to get a fair hearing within a system in which they may feel lost. These families not infrequently find themselves repeating with the authorities their own way of relating with each other. The authorities may come to represent the family's own unsatisfactory parents, which may make the family themselves feel constantly humiliated, punished or misunderstood by those around them. They may then in turn wish to attack and punish those whom they see as responsible for unnecessary persecution. I am not convinced that mental health workers or lawyers sufficiently appreciate this kind of dilemma. However, it is quite possible that even with more appreciation of these issues by the professionals, these families would continue to make those around them feel muddled; for this feeling may mainly reflect the family's own confusion; and it may simply have to be tolerated by the professionals. It is certainly my impression that a considerable part of our psychotherapeutic treatment of these families consists of tolerating and understanding states of confusion in ourselves and in those we treat.

One common finding in the treatment of these families is that workers may be so caught in the confusion and uncertainty that they forget the basic principle of this work, that of keeping the best interests of the child in mind. Instead of offering a safe monitoring or treating framework, the workers' behaviour and attitudes may merely reflect the parent's pathology. In order to provide a safe professional framework that keeps in the forefront the rights and needs of the child I think that there are several essential elements, including the following:

\section{Clear lines of professional responsibility}

It would seem to be of paramount importance for the various workers to know what they are responsible for, and the limits of that responsibility. For example, as consultant to the Family Unit, one of my main responsibilities is the admission and discharge of patients. I cannot be forced to admit someone I think is unsuitable for our treatment, neither can I force a Judge to admit someone when the Judge is against rehabilitation. We in the Unit are always mindful that we have an enormous clinical responsibility when taking on these difficult families, and yet we are also aware that the ultimate responsibility for the child's future rests in other hands. We may make recommendations, but the court ultimately decides what will happen. In practice, it is my experience that the courts are very keen on finding a sensible solution to a child and family problem, where at all possible; and if our Unit can be of help, then the courts are usually keen to use us. The fact that there is no comparable unit with our depth of experience and expertise, and that can offer day by day observations of family functioning, obviously puts us in a strong position to support rehabilitation, or to provide a strong 
and clear clinical opinion about the future of a child. However, we need the backing of social work agencies as much as backing from the courts, for we have to work on a regular basis with them. As these families are constantly producing tensions in the workers around them, there needs to be an ongoing relationship between workers in order to understand and process these tensions. We in the Unit want the social workers to do their job, to be clear about their responsibilities and to remind us of ours.

\section{Effective communication between workers}

This follows from the point I have just made, but can only be established if different workers are clear about their roles and responsibilities. Workers in different settings, in different institutions and offices, may be skilled in working with their clients, but not necessarily skilled in working with professionals from other institutions. Effective communication may only be possible when structured meetings are arranged to examine specific issues to do with a family. If there is too much reliance on informal passing on of information, it is my experience that very soon there arise considerable distortions in people's perceptions of each other and in the nature of the information itself. It is also my experience that the passing on of information is facilitated if there is a clear focus of work agreed upon by all parties.

\section{Promoting of mutual trust}

We have found that successful work with these families depends on a process of trust developing between the families and the network of professionals both within our setting and outside it. However confront- ing we may have to be with the parents, if the confrontation takes place within an essentially trusting context, then change in the parents may take place. My two previous points imply that the workers have to develop trust in one another for treatment to be effective. I am also suggesting that the work with the families should also take place with the assumption that we are trying to develop a trusting relationship with them. These are often families where trust has broken down between the parents, and between the parents and the children. In addition, many parents have never had an experience of a trusting relationship. I would argue that there is all the more reason to offer them the opportunity to make an intimate emotional contact with professional workers, in order to help them work through some of their previous disappointments. I think that what I am suggesting as the basis of our treatment may have implications for the way that the law is currently organised. One may wonder whether or not the legal system promotes or hinders trust from developing where there is some hope of change.

\section{References}

Bromley, P. \& Lowe, N. (1987) Bromley's Family Law (seventh edition). London: Butterworths.

DHSS (1987) The Law on Child Care and Family Services. London: HMSO.

KENNEDY, R. et al (1987) The Family as In-Patient. London: Free Association Books.

- (1988) The treatment of child abuse in an in-patient setting. Bulletin of the Royal College of Psychiatrists, 12, 361-366.

LOWE, N. \& WHITE, R. (1986) Wards of Court (second edition). London: Barry Rose. 